\title{
Morphometric study of the triangle of Petit in human fetuses
}

\author{
Magdalena Grzonkowska ${ }^{A-D}$, Mateusz Badura ${ }^{A-D}$, Mariusz Baumgart ${ }^{A-C}$, Anna Wiczołek ${ }^{B, C}$, \\ Jakub Lisiecki ${ }^{B}$, , Maciej Biernacki ${ }^{B, C}$, Michał Szpinda ${ }^{D-F}$ \\ Department of Normal Anatomy, Ludwik Rydygier Collegium Medicum in Bydgoszcz, Nicolaus Copernicus University in Toruń, Poland \\ A - research concept and design; $\mathrm{B}$ - collection and/or assembly of data; $\mathrm{C}$ - data analysis and interpretation; \\ $D$ - writing the article; $E$ - critical revision of the article; $F$ - final approval of the article
}

Address for correspondence

Michał Szpinda

E-mail: kizanat@cm.umk.pl

\section{Funding sources}

None declared

\section{Conflict of interest}

None declared

Received on April 6, 2016

Reviewed on April 25, 2016

Accepted on May 27, 2016
DOI

$10.17219 /$ acem $/ 63403$

\section{Copyright}

Copyright by Author(s)

This is an article distributed under the terms of the

Creative Commons Attribution Non-Commercial License

(http://creativecommons.org/licenses/by-nc-nd/4.0/)

\section{Abstract}

Background. The inferior lumbar triangle of Petit is bounded by the iliac crest, lateral border of the latissimus dorsi and the medial border of the external oblique.

Objectives. In the present study, we aimed to quantitatively examine the base, sides, area, and interior angles of the inferior lumbar triangle in the human fetus so as to provide their growth dynamics.

Material and methods. Using anatomical dissection, digital image analysis (NIS-Elements AR 3.0), and statistics (Student's t-test, regression analysis), we measured the base, 2 sides, area and interior angles of Petit's triangle in 35 fetuses of both sexes (16 male, 19 female) aged 14-24 weeks.

Results. Neither sex nor laterality differences were found. All the parameters studied increased commensurately with age. The linear functions were computed as follows: $y=-0.427+0.302 \times$ age for base, $y=1.386+0.278 \times$ age for medial side, $y=0.871+0.323 \times$ age for lateral side, and $y=-13.230+$ $1.590 \times$ age for area of the Petit triangle.

Conclusions. In terms of geometry, Petit triangle reveals neither male-female nor right-left differences. An increase in both lengths and area of the inferior lumbar triangle follows proportionately. The Petit triangle is an acute one in the human fetus.

Key words: digital-image analysis, Petit triangle, inferior lumbar triangle, side, area 


\section{Introduction}

The inferior lumbar triangle of Petit is a topographical element of the lower back with an area of minor resistance of the posterior abdominal wall. The base of that triangle is limited by the iliac crest, with the opposite apex directed toward the inferior angle of the scapula, the medial side is constituted by the lateral border of the latissimus dorsi, and the lateral side is composed of the medial border of the external oblique muscle. The floor of the Petit triangle is part of the internal oblique muscle covered with the superficial fascia and subcutaneous tissue..$^{1-7}$

Precise data on the quantitative anatomy of the inferior lumbar triangle may be useful in anesthesiology, especially in anesthesia of the transversus abdominis plane (TAP), and in fetal surgery. TAP is located in the anterior abdominal wall between the transversus abdominis and the internal oblique muscle, and includes the lower intercostal nerves with concomitant blood vessels destined for the anterolateral abdominal wall. ${ }^{6-9}$ To date, autopsy material of adult individuals only has been used for the geometrical analysis of Petit's triangle. , 7,10 Therefore, this is the first report in the professional literature to present a numerical analysis of Petit's triangle in human fetuses.

The objectives of the present study were:

- morphometric analysis of the inferior lumbar triangle in human fetuses with respect to its linear and planar parameters, and interior angles in order to determine their normative values at varying gestational ages;

- establishing the possible sexual and bilateral differences regarding the analyzed parameters;

- establishing developmental dynamics for the analyzed parameters, including mathematical growth models best matched for fetal age.
A
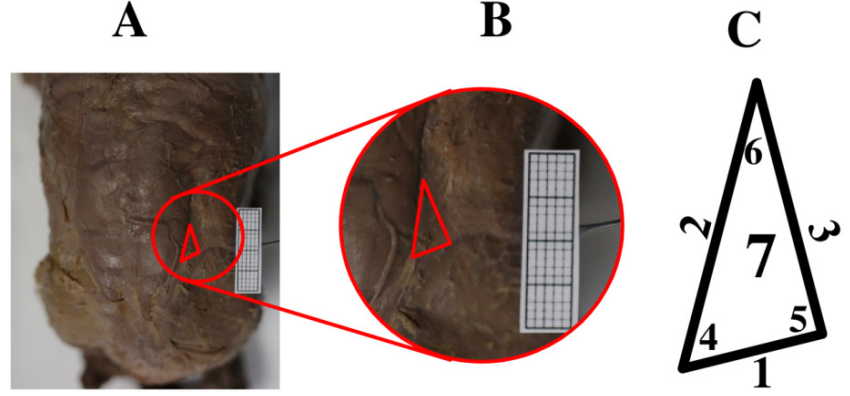

Fig. 1. Petit's triangle (A, B) in a female fetus at 24 weeks showing the measured parameters (C)

\section{Material and methods}

The study material consisted of 35 fetuses of both sexes (16 males and 19 females) aged 14-24 weeks of fetal life, originating from spontaneous abortions and stillbirths. The material was acquired before the year 2000 and remains part of the specimen collection of the Department of Normal Anatomy of Nicolaus Copernicus University in Torun. This experiment was sanctioned by the Bioethics Committee of the Nicolaus Copernicus University in Toruń (approval No. KB 186/2016). The fetal age was determined on the crown-rump length. Table 1 lists the characteristics of the study group, including age, number and sex of the fetuses.

Using anatomical dissection, the inferior lumbar triangle was visualized on both sides, then recorded using a Sony $\alpha 330$ digital camera and subjected to morphometric analysis using digital image-analysis (NIS-Elements AR 3.0 software, Nikon, Minato, Japan). In each Petit's triangle, the following 7 parameters were measured (Fig. 1):

Table 1. Characteristics (age, number and sex) of the fetuses studied

\begin{tabular}{|c|c|c|c|c|c|c|c|}
\hline \multirow{2}{*}{$\begin{array}{l}\text { Gestational age } \\
\text { weeks (Hbd-life) }\end{array}$} & \multicolumn{4}{|c|}{ Crown-rump length (mm) } & \multirow{2}{*}{$\begin{array}{l}\text { Number of } \\
\text { fetuses }\end{array}$} & \multicolumn{2}{|c|}{ Sex } \\
\hline & mean & SD & $\min$ & $\max$ & & $\sigma^{3}$ & $q$ \\
\hline 14 & 88.00 & & 88.0 & 88.0 & 1 & 0 & 1 \\
\hline 15 & 94.67 & 2.31 & 92.0 & 96.0 & 3 & 2 & 1 \\
\hline 16 & 114.75 & 1.71 & 113.0 & 117.0 & 4 & 1 & 3 \\
\hline 17 & 123.00 & 5.00 & 118.0 & 128.0 & 3 & 2 & 1 \\
\hline 18 & 139.33 & 3.21 & 137.0 & 143.0 & 3 & 1 & 2 \\
\hline 19 & 152.00 & 4.12 & 145.0 & 155.0 & 5 & 2 & 3 \\
\hline 20 & 164.00 & 2.65 & 162.0 & 167.0 & 3 & 1 & 2 \\
\hline 21 & 175.00 & 2.94 & 171.0 & 178.0 & 4 & 1 & 3 \\
\hline 22 & 188.67 & 2.31 & 186.0 & 190.0 & 3 & 2 & 1 \\
\hline 23 & 197.00 & 4.18 & 192.0 & 201.0 & 5 & 4 & 1 \\
\hline 24 & 206.00 & & 206.0 & 206.0 & 1 & 0 & 1 \\
\hline Total & & & & & 35 & 16 & 19 \\
\hline
\end{tabular}

đo-male; + - female. 
1. base - length of the iliac crest $(\mathrm{mm})$;

2. medial side - length of the lateral border of the latissimus dorsi $(\mathrm{mm})$;

3. lateral side - length of the medial border of the external oblique muscle $(\mathrm{mm})$;

4. basomedial angle - between the iliac crest and the medial border of the external oblique muscle;

5. basolateral angle - between the iliac crest and the lateral border of the latissimus dorsi;

6. apical angle - between the medial border of the external oblique and the lateral border of the latissimus dorsi;

7. area - calculated semiautomatically after outlining the triangle $\left(\mathrm{mm}^{2}\right)$.

The obtained numerical data was analyzed statistically using Statistica v. 12.5 software (StatSoft Inc., Tulsa, USA). The results are expressed as arithmetic means with standard deviations (SD). To compare the means, Student's t-test for dependent (left-right) and independent (malefemale) variables, and one-way analysis of variance were used. The characterization of the developmental dynamics of the analyzed parameters was based on linear and curvilinear regression analysis. The match between the estimated curves and numerical data was evaluated due to coefficient of determination $\left(R^{2}\right)$. Differences were considered significant at $\mathrm{p}<0.05$.

\section{Results}

The entire fetal material unveiled the inferior lumbar triangle on both sides within its typical boundaries: a base at the iliac crest, a medial side constituted by the lateral border of the latissimus dorsi, and a lateral side constituted by the medial border of the external oblique muscle.

The statistical analysis revealed neither sexual nor bilateral differences concerning all the analyzed parameters. Therefore, we investigated the developmental dynamics of the 7 established parameters without taking sex or age into account. The numerical data of the inferior lumbar triangle has been presented in tables, as follows: its base and 2 sides in Table 2, its interior angles in Table 3, and its area in Table 4.

The developmental dynamics of the base, sides and area of the inferior lumbar triangle followed linear functions, as displayed in Table 5.

\section{Discussion}

The inferior lumbar triangle is an area of minor resistance of the posterior abdominal wall and a gateway to lower lumbar hernias. ${ }^{1-7}$ As reported, the most tenuous point of the lumbar triangle is the Hartmann fissure located at its apex. ${ }^{11-13}$ Lower lumbar hernias may be both congenital and acquired, constituting 20\% and 80\% of cases, respectively. ${ }^{4,5,10,11,14}$ Congenital defects of the posterior abdominal wall are the most common reasons for the lower lumbar hernias in children. ${ }^{15,16}$ In turn, acquired lower lumbar hernias are divisible into primary and secondary types, the former resulting from an excessive tonus of abdominal musculature, e.g., in obese elderly people, and the latter being a consequence of damage to the abdominal muscles and resulting in scar formation. ${ }^{16-18}$ In adults, lower lumbar hernias affect men 3 times more often than women, especially those aged 40-60 years, and with a greater tendency to occur on the right side. ${ }^{15,19-22}$ The main symptom reported by patients is a pain or discomfort in the lumbar region, usually when tightening the abdominal musculature. ${ }^{11,15,20-22}$ However, lower lumbar hernias may be asymptomatic as well. ${ }^{14,20,21}$

In anesthesia, the inferior lumbar triangle is a natural and safe anatomical gateway to transversus abdominis plane punctures, as there are no neurovascular structures.,10 The transversus abdominis plane block was developed in 2001 by Rafi for an easy and effective anesthesia within the hypogastrium, especially in cesarean sections, inguinal hernia surgery and laparoscopic procedures. ${ }^{6,23} \mathrm{Heb}-$ bard et al. described a method of TAP anesthesia through a block of the lower intercostal nerves that are readily accessible via the inferior lumbar triangle. ${ }^{24}$ The Petit triangle is also conducive in urology, neurosurgery and surgery as an approach to the retroperitoneal space. ${ }^{25-28}$

In this study, the inferior lumbar triangle was bilaterally present in all human fetuses considered. In an autopsy study conducted in adults, Loukas et al. observed Petit's triangle in $82.5 \%$ of cases, and Starczewski in $89 \%$ of cases, somewhat more often on the left side. ${ }^{10,28}$ In cases with absent lumbar triangles, the latissimus dorsi was overlapped by the external oblique muscle.

As presented in the current study, in terms of quantity, the Petit triangle did not demonstrate any sexual or bilateral differences. Between weeks 14 and 24 of gestation, the dimensions of the inferior lumbar triangle increased as follows: its base from 3.63 to $6.91 \mathrm{~mm}$, its medial side from 5.24 to $6.84 \mathrm{~mm}$, and its lateral side from 5.40 to $8.82 \mathrm{~mm}$. These parameters were deliberated in adults by Loukas et al., Jankovic et al. and Starczewski et al., who also did not note any sexual differences in this aspect. ${ }^{6,10,28}$ As reported by Loukas et al., in the inferior lumbar triangles on the right and left sides, the mean base measured at the iliac crest was $2.57 \mathrm{~cm}$ and $3.1 \mathrm{~cm}$, respectively, the mean medial side measured at the latissimus dorsi was $3.44 \mathrm{~cm}$ and $4.57 \mathrm{~cm}$, respectively, and the mean lateral side measured at the external oblique muscle was $4.53 \mathrm{~cm}$ and $3.25 \mathrm{~cm}$, respectively. ${ }^{10}$ In the same study, symmetrical triangles were observed most often (25\%) with type I, less often (17.5\%) with type II, and least often (3.7\%) with type III, according to the classification by Loukas et al. detailed below..$^{10}$ In addition, the inferior triangles located on the left side were larger. Jankovic et al., in 26 individuals aged 72-102 years with the mean height of $161.8 \mathrm{~cm} \pm 9.9 \mathrm{~cm}$, demonstrated that the triangle base 


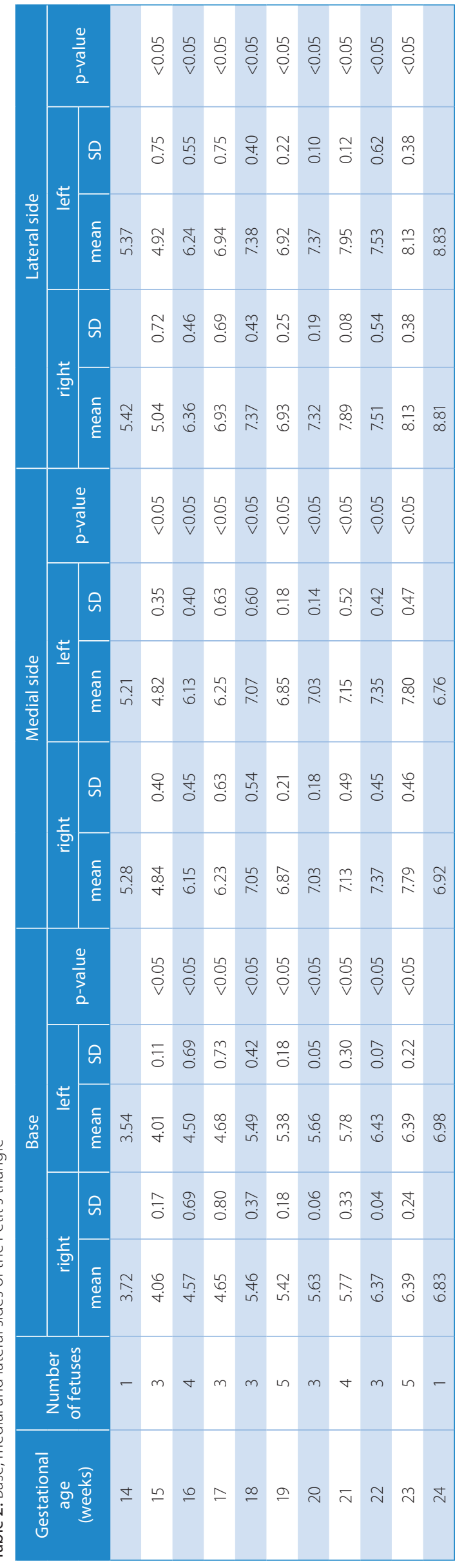

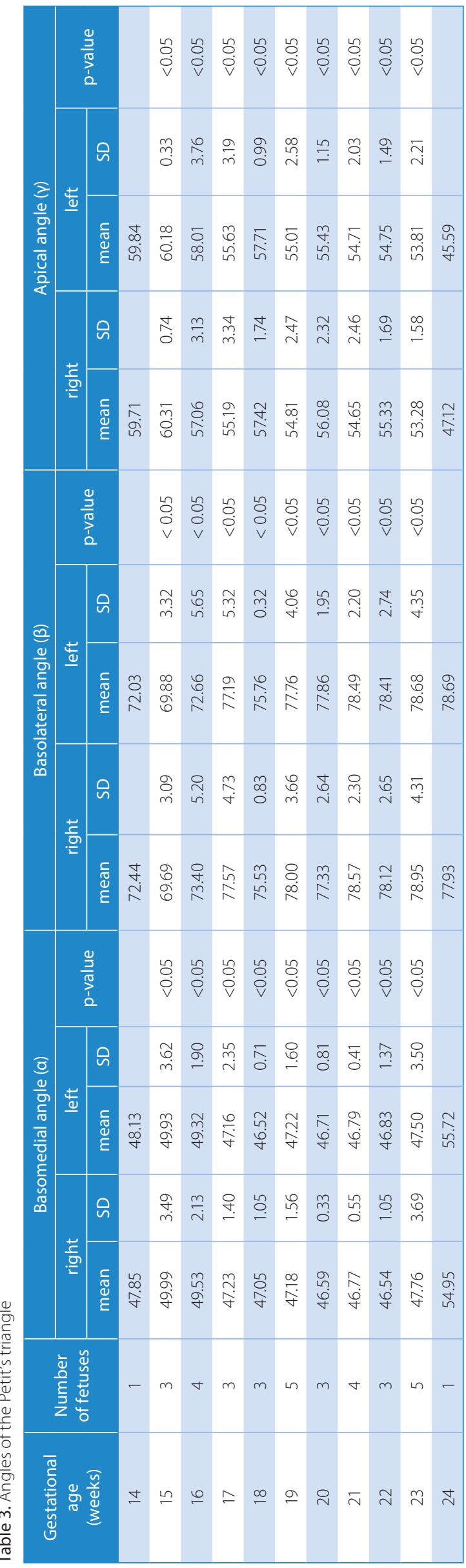


Table 4. Area of the Petit's triangle

\begin{tabular}{|c|c|c|c|c|c|c|c|c|c|c|c|c|}
\hline \multirow{3}{*}{$\begin{array}{c}\text { Gestational } \\
\text { age } \\
\text { (weeks) }\end{array}$} & \multirow{3}{*}{$\begin{array}{l}\text { Number } \\
\text { of fetuses }\end{array}$} & \multicolumn{9}{|c|}{ Area $\left(\mathrm{mm}^{2}\right)$} & \multicolumn{2}{|c|}{ Sex } \\
\hline & & \multicolumn{2}{|c|}{ mean } & \multicolumn{2}{|c|}{ SD } & \multirow{2}{*}{$p$-value } & \multicolumn{2}{|c|}{$\min$} & \multicolumn{2}{|c|}{$\max$} & \multirow{2}{*}{$\hat{\sigma}$} & \multirow{2}{*}{ 운 } \\
\hline & & right & left & right & left & & right & left & right & left & & \\
\hline 14 & 1 & 8.92 & 9.20 & & & & 8.92 & 9.20 & 8.92 & 9.20 & 0 & 1 \\
\hline 15 & 3 & 9.15 & 8.87 & 1.53 & 1.37 & $<0.05$ & 7.51 & 7.44 & 10.56 & 10.18 & 2 & 1 \\
\hline 16 & 4 & 13.36 & 13.04 & 2.76 & 2.84 & $<0.05$ & 10.43 & 10.01 & 17.09 & 16.87 & 1 & 3 \\
\hline 17 & 3 & 14.26 & 14.38 & 3.55 & 3.38 & $<0.05$ & 10.16 & 10.51 & 16.51 & 16.70 & 2 & 1 \\
\hline 18 & 3 & 18.20 & 18.34 & 2.02 & 2.33 & $<0.05$ & 16.08 & 15.86 & 20.11 & 20.50 & 1 & 2 \\
\hline 19 & 5 & 17.19 & 17.05 & 0.74 & 0.80 & $<0.05$ & 16.35 & 16.28 & 18.30 & 18.21 & 2 & 3 \\
\hline 20 & 3 & 18.54 & 18.69 & 0.49 & 0.26 & $<0.05$ & 18.16 & 18.53 & 19.10 & 18.99 & 1 & 2 \\
\hline 21 & 4 & 19.77 & 19.90 & 1.31 & 1.46 & $<0.05$ & 18.10 & 17.88 & 21.32 & 21.41 & 1 & 3 \\
\hline 22 & 3 & 21.39 & 21.57 & 1.66 & 1.86 & $<0.05$ & 19.47 & 19.43 & 22.42 & 22.82 & 2 & 1 \\
\hline 23 & 5 & 23.22 & 23.25 & 1.52 & 1.50 & $<0.05$ & 20.80 & 21.01 & 24.80 & 25.14 & 4 & 1 \\
\hline 24 & 1 & 23.25 & 23.23 & & & & 23.25 & 23.23 & 23.25 & 23.23 & 0 & 1 \\
\hline \multicolumn{11}{|l|}{ Total } & 16 & 19 \\
\hline
\end{tabular}

$\lesssim$ - male; $q$ - female.

Table 5. The growth dynamics of the base, sides and area of the Petit triangle

\begin{tabular}{|l|c|c|c|c|}
\multicolumn{1}{|c|}{ Parameter } & Regression equation & $R^{2}$ & $F$ & $p$-value \\
\hline Base $(\mathrm{mm})$ & $y=-0.427+0.302 \times$ age & 0.843 & 364.83 & 0.000 \\
\hline Medial side $(\mathrm{mm})$ & $y=1.386+0.278 \times$ age & 0.702 & 160.15 & 0.000 \\
\hline Lateral side $(\mathrm{mm})$ & $y=0.871+0.323 \times$ age & 0.739 & 192.88 & 0.000 \\
\hline Area $\left(\mathrm{mm}^{2}\right)$ & $y=-13.230+1.590 \times$ age & 0.858 & 412.27 & 0.000 \\
\hline
\end{tabular}

was $2.3 \mathrm{~cm} \pm 1.03 \mathrm{~cm}$, the medial side was $2.2 \mathrm{~cm} \pm 1.38 \mathrm{~cm}$, and the lateral side was $3.3 \mathrm{~cm} \pm 1.36 \mathrm{~cm} .{ }^{6}$ Numerical data by Starczewski indicated that for the right and left sides, the mean triangle base was $24.8 \mathrm{~mm} \pm 11.8 \mathrm{~mm}$ and $25.3 \mathrm{~mm} \pm 9.0 \mathrm{~mm}$, respectively, the mean medial side was $24.3 \mathrm{~mm} \pm 9.9 \mathrm{~mm}$ and $25.1 \mathrm{~mm} \pm 8.7 \mathrm{~mm}$, respectively, and the mean lateral side was $33.0 \mathrm{~mm} \pm 10.1 \mathrm{~mm}$ and $32.2 \mathrm{~mm} \pm 11.0 \mathrm{~mm}$, respectively. ${ }^{28}$

Of note, the present study has been the first report in the literature to explicitly display mathematical growth models of the inferior lumbar triangle as a function of fetal age. Its morphometric parameters increased proportionally, following the functions: $y=-0.427+0.302 \times$ age for base, $y=1.386+0.278 \times$ age for medial side, and $y=0.871$ $+0.323 \times$ age for lateral side of the inferior lumbar triangle.

In our study, the basomedial angle of the lumbar triangle was between $47.85^{\circ}$ and $54.95^{\circ}$ on the right side, and between $48.13^{\circ}$ and $55.72^{\circ}$ on the left side. The basolateral angle was between $72.44^{\circ}$ and $77.93^{\circ}$ on the right side, and between $72.03^{\circ}$ and $78.69^{\circ}$ on the left side. Obviously, the basal angles determined the apical angle, the value of which was between $59.71^{\circ}$ and $47.12^{\circ}$ on the right, and between $59.84^{\circ}$ and $45.59^{\circ}$ on the left. Furthermore, all observed interior angles were smaller than $90^{\circ}$, and thus all inferior lumbar triangles observed in this study were acute ones. As reported by Starczewski et al., the basomedial angle was $47^{\circ} \pm 15^{\circ}$ on the right and $49^{\circ} \pm 17^{\circ}$ on the left. ${ }^{28}$ In turn, the basolateral angle was $84^{\circ} \pm 29^{\circ}$ on the right side and $81^{\circ} \pm 26^{\circ}$ on the left side. These authors reported 2 types of the Petit triangle: acute (59\%) and obtuse (41\%).

In our study, at the fetal age of 14-24 weeks, the inferior lumbar triangle area increased from $8.92 \mathrm{~mm}^{2}$ to $23.25 \mathrm{~mm}^{2}$ on the right, and from $9.20 \mathrm{~mm}^{2}$ to $23.23 \mathrm{~mm}^{2}$ on the left side. This increase in area of Petit's triangle followed the linear function: $y=-13.230+1.590 \times$ age. Based on its area value, Loukas et al. described 4 types of the inferior lumbar triangle: type I (43.7\%) - small with the area of up to $8 \mathrm{~cm}^{2}$; type II (26.2\%) -intermediate with the area between 8 and $12 \mathrm{~cm}^{2}$, and type III (12.5\%) - large, with the area exceeding $12 \mathrm{~cm}^{2}$; type IV (17.5\%) was defined as a lack of the Petit triangle. ${ }^{10}$ Starczewski introduced a 3-degree classification of the Petit triangle, according to its area. ${ }^{28}$ Type I or small (20\%) involved triangles with their area not exceeding $3 \mathrm{~cm}^{2}$; type II or intermediate (44\%) included triangles with their area of 3 to $6 \mathrm{~cm}^{2}$; type III or large (36\%) referred to triangles with their area above $6 \mathrm{~cm}^{2}$. The mean Petit triangle area was $3.6 \mathrm{~cm} \pm 2.2 \mathrm{~cm}^{2}$. Similarly, in the study by Jankovic et al., the mean Petit triangle area was $3.63 \mathrm{~cm} \pm 1.93 \mathrm{~cm}^{2} .{ }^{6}$ Furthermore, the authors demonstrated that the inferior lumbar triangle was enormously variable in its size and shape, and was located more medial than it had been previously expected. The orthocenter of the Petit triangle was, on average, $6.9 \mathrm{~cm}$ more posterior 
with relation to the mid-axillary line, while the measurements taken superficially were somewhat smaller $(9.3 \mathrm{~cm})$. Due to the observed differences in size and shape of Petit's triangles, the authors concluded that the presumptive location of the inferior lumbar triangle may prevaricate the physician when administering TAP anesthesia.

\section{Conclusions}

In terms of geometry, Petit's triangle reveals neither male-female nor right-left differences. An increase in both lengths and area of the inferior lumbar triangle follows proportionately. The Petit triangle is acute in the human fetus.

\section{References}

1. Grauls A, Lallemand B, Krick M. The retroperitoneoscopic repair of a lumbar hernia of Petit - Case report and review of literature. Acta Chir Belg. 2004;104:330-334.

2. Lawdahl RB, Moss N, van Dykke JA. Inferior lumbar (Petit's) hernia. AJR. 1986;147:744-755.

3. Faro SH, Racette CD, Lally JF, Wills JS, Mansoory A. Traumatic lumbar hernia: CT diagnosis. AJR. 1990;154:757-759.

4. Bhasin SK, Khan AB, Sharma S. Bilateral Petit's triangle hernia. JK SCience. 2006;8(3):163-164.

5. Bigolin AV, Rodrigues AP, Trevisan CG, et al. Petit lumbar hernia - A double layer technique for tension - Free repair. Int Surg. 2014;99: 556-559.

6. Jankovic ZB, du Feu FM, McConnel P. An anatomical study of the transversus abdominis plane block: Location of the lumbar triangle of Petit and adjacent nerves. Anesth Analg. 2009;109(3):981-985.

7. Starczewski K, Ziętek-Czeszak A, Kamiński M, Ziętek Z. Transverse abdominal plane - Anatomical and clinical aspects. Ann Acad Med Stetin. 2014;60(1):16-19.

8. Manatakis DK, Stamos N, Agalianos Ch, Karvelis MA, Gkiaourakis M, Davides D. Transient femoral nerve palsy complicating "blind" transversus abdominis plane block. Case Rep Anesthesiol. 2013;1-3.

9. Ibrahim M, El Shamaa H. Efficacy of ultrasound-guided oblique subcostal transversus abdominis plane block after laparoscopic sleeve gastrectomy: A double blind, randomized, placebo controlled study. Eg J Anaesth. 2014;30:285-292.
10. Loukas M, Tubbs RS, El-Sedfy A, et al. The clinical anatomy of the triangle of Petit. Hernia. 2007;11(5):441-444.

11. Burt BM, Afifi HY, Wantz GE, Barie PS. Traumatic lumbar hernia: Report of cases and comprehensive review of the literature. J Trauma. 2004; 57(6):1361-1370.

12. Ipek T, Eyuboglu E, Aydingoz O. Laparoscopic management of inferior lumbar hernia (Petit triangle hernia). Hernia. 2005;9:184-187.

13. Hemmer PH, van Leuuwen BL. Image of month diagnosis. Lumbar hernia in the triangle of Petit. Arch Surg. 2012;147:485-486.

14. Singh M, Kumar A, Nag S. Inferior lumbar hernia: Case report. IOSRJDMS. 2014;13(2):16-18.

15. Baker ME, Weinerth JL, Andriani RT, Cohan RH, Dunnick NR. Lumbar hernia: Diagnosis by CT. AJR. 1987;148(3):565-467.

16. Moreno-Egea A, Baena EG, Calle MC, Martinez JA, Albasini JL. Controversies in the current management of lumbar hernias. Arch Surg. 2007;142(1):82-88.

17. Gagner M, Milone L, Gumbs A, Turner P. Laparoscopic repair of left lumbar hernia after laparoscopic left nephrectomy. JSLS. 2010;14(3): 405-409.

18. Tavares-de la Paz LA, Martínez-Ordaz JL. Lumbar hernia. Case report and literature review. Cir Cir. 2007;75(5):381-384.

19. Alves A Jr, Maximiano L, Fujimura I, Pires PW, Birolini D. Grynfelt hernia. Arq Gastroenterol. 1996;33:32-35.

20. Cavallaro G, Sadighi A, Miceli M, Burza A, Carbone G, Cavallaro A. Primary lumbar hernia repair: The open approach. Eur Surg Res. 2007; 39(2):88-92.

21. Di Carlo I, Toro A, Sparatore F, Corsale G. Lumbar hernia repaired using a new technique. Am Surg. 2007;73(1):54-57.

22. Palanivelu C, Rangarajan M, John SJ, Madankumar MV, Senthilkumar K. Laparoscopic transperitoneal repair of lumbar incisional hernias: A combined suture and "doublemesh" technique. Hernia. 2008; 12(1):27-31.

23. Rafi AN. Abdominal field block: A new approach via the lumbar triangle. Anaesthesia. 2001;56(10):1024-1026.

24. Hebbard P, Fujiwara Y, Shibata Y, Royse C. Ultrasound guided transversus abdominis plane block. Anaesth Intense Care. 2007;35(4):616-617.

25. Cussenot O, Bourrier P, Bassi S, et al. Anatomic study of the lumbar region applied to multiplanar imaging techniques: Importance and use of oblique vertical sections. Surg Radiol Anat. 1994;16:287-291.

26. Crouse H. The triangle of Petit in kidney surgery. Ann Surg. 1915;62: 451-455.

27. Moreno-Egea A, Aguayo Jl. Ambulatory laparoscopic repair of inferior or Petit hernia: A case report. Surg Endosc. 2002;16:1107-1107.

28. Starczewski K. Trójkąt lędźwiowy - budowa, topografia oraz zmienność w aspekcie dostępu do znieczuleń przestrzeni poprzecznej brzucha [doctoral thesis]. Szczecin, Poland: Pomorski Uniwersytet Medyczny w Szczecinie; 2014. 